$17^{\circ}$ ERGODESIGN

\& USIHC 2019

PUC-Rio, 11 a 13 de dezembro

Rio de Janeiro, RJ, Brasil $17^{\circ}$ Ergodesign - Congresso Internacional de Ergonomia e Usabilidade

de Interfaces Humano Tecnológica: Produto, Informações Ambientes Construídos e Transporte

$17^{\circ}$ USIHC - Congresso Internacional de Ergonomia e Usabilidade

de Interfaces Humano Computador

\title{
Pesquisa exploratória com inquirições aos especialistas em projeto de produtos
}

\section{Exploratory research with product design experts inquiries}

\author{
MOREIRA RANGEL, Márcia \\ Instituto Federal de Educação, Ciência e Tecnologia do Sudeste de Minas Gerais, Doutora em Design \\ marcia.rangel@ifsudestemg.edu.br \\ DE OLIVEIRA CAMACHO, Nádia \\ Instituto Federal de Educação, Ciência e Tecnologia do Sudeste de Minas Gerais, Mestra em \\ Ambiente Construído \\ nadia.camacho@ifsudestemg.edu.br \\ KUHN, Samantha Pinheiro \\ Instituto Federal de Educação, Ciência e Tecnologia do Sudeste de Minas Gerais, bolsista \\ PIBIC/FAPEMIG \\ samanthapkuhn@gmail.com \\ MENDES, Lyandra \\ Instituto Federal de Educação, Ciência e Tecnologia do Sudeste de Minas Gerais, bolsista \\ PIBIC/FAPEMIG \\ lyandramendes35@gmail.com
}

\section{RESUMO}

Este trabalho se insere no âmbito de uma pesquisa exploratória do campo da Ergonomia que objetiva investigar, em escala regional, dados relativos à escolha da cor nos produtos residenciais a partir do ponto de vista dos profissionais que atuam no segmento. O aporte teórico para o desenvolvimento da pesquisa se deu por revisão bibliográfica que aborda os conceitos das funções práticas, estéticas e simbólicas dos produtos. O levantamento da opinião de especialistas sobre a inserção da cor em seus produtos se deu por meio de aplicação de questionários. A partir das respostas obtidas foi possível compreender práticas por meio do uso funcional da cor que revelaram indicadores que podem contribuir para o desenvolvimento de projetos de produtos residenciais. Em linhas gerais, os resultados apontaram para uma necessidade de investigação maior em pesquisas futuras mas já foi possível observar, na amostra investigada, convergência entre os conceitos apresentados nas bibliografias estudadas com a prática profissional dos especialistas entrevistados.

Ergonomia, Projeto de Produto, Funções, Cor. 


\section{$17^{\circ}$ ERGODESIGN \& USIHC 2019 \\ PUC-Rio, 11 a 13 de dezembro \\ Rio de Janeiro, RJ, Brasil}

$17^{\circ}$ Ergodesign - Congresso Internacional de Ergonomia e Usabilidade de Interfaces Humano Tecnológica: Produto, Informações Ambientes Construídos e Transporte

$17^{\circ}$ USIHC - Congresso Internacional de Ergonomia e Usabilidade de Interfaces Humano Computador

\begin{abstract}
This work includes a scope of an exploratory research in the field of Ergonomics that aims to investigate, on a regional scale, data related to the choice of residential products from the point of view of professionals working in the segment. The theoretical support for the development of the research was given by literature review that addresses the concepts of practical, aesthetic and symbolic functions of the products. The opinion of experts on the insertion of their products was obtained through the application of questionnaires. From the selected answers, it was possible to understand the practices through the functional use that shows indicators that can contribute to the development of residential product projects. In general, the results pointed to a need for greater investigation in researches that were already possible, but which were observed, in the investigated sample, in the convergence between the concepts presented in the bibliographies studied with a professional practice of the interviewed specialists.
\end{abstract}

Human Factors, Product design, functions, color.

\title{
1. INTRODUÇÃO
}

Todo objeto/produto possui uma linguagem a ser compreendida como um conjunto de elementos associados segundo regras de formação e de transformação. Assim, o produto possui uma dimensão sintática descrita pelo arranjo de seus componentes. Pode-se compreender essa dimensão na forma como o produto se apresenta e que pode ser descrito pelo ordenamento de seus elementos constituintes. É a estrutura do conjunto do produto. Como as partes se identificam e se articulam material e formalmente. Abrange tanto a estrutura do produto quanto o seu funcionamento técnico (BRAIDA; NOJIMA, 2014). De acordo com Niemeyer, "[...] a sintaxe inclui tanto a análise da construção técnica do produto quanto à análise de detalhes visuais [...] também podem ser descritos como aspectos da composição formal” (NIEMEYER, 2003, p.46, apud BRAIDA; NOJIMA, 2014, p. $50)$.

A linguagem expressa por um produto deve ser passível de compreensão do usuário e pode estar vinculada às funções articuladas por Löbach (2001). Segundo Löbach (2001, p.55) "[...] no processo de utilização se satisfazem as necessidades do usuário dotando-se o produto de certas funções". Para Löbach (2001, p.54) ao empregar o conceito de função, o mundo dos objetos se faz mais compreensível para o homem.

A pesquisa em Ergonomia visa compreender o universo do objeto de estudo para levantar as situações da interação humano/tarefa, considerando como tarefa o escopo de ações e percepções que envolvem tal interação. A cor é um item de projeto cuja amplitude de usos ainda é pouco explorada nos estudos acerca da projetação dos produtos, embora tenha participação ativa na interação humano/tarefa no que tange ao uso dos produtos, com consequente influência na prática profissional.

Este estudo apresenta cruzamento de conceitos extraídos de revisão bibliográfica com dados revelados por meio de questionários aplicados em profissionais (arquitetos e designers) que projetam mobiliário, recorte do produto desenvolvido na pesquisa. Buscou-se levantar a opinião de especialistas sobre a inserção da cor em seus produtos. A partir das respostas obtidas foi possível compreender práticas por meio do uso funcional da cor que revelaram indicadores que podem contribuir para o desenvolvimento de projetos de produtos residenciais. Como principal resultado, 
$17^{\circ}$ ERGODESIGN \& USIHC 2019

PUC-Rio, 11 a 13 de dezembro

Rio de Janeiro, RJ, Brasil $17^{\circ}$ Ergodesign - Congresso Internacional de Ergonomia e Usabilidade de Interfaces Humano Tecnológica: Produto, Informações Ambientes Construídos e Transporte

$17^{\circ}$ USIHC - Congresso Internacional de Ergonomia e Usabilidade

de Interfaces Humano Computador

aponta-se a necessidade de investigação maior em pesquisas futuras mas já foi possível observar, na amostra investigada, convergência entre os conceitos apresentados nas bibliografias estudadas com a prática profissional dos especialistas entrevistados.

\section{REFERENCIAL TEÓRICO}

Löbach (2001) argumenta que um bom produto de design deve atender as três funções básicas, quais sejam: a função prática, a função estética e a função simbólica, no entanto, apenas uma se sobressai. Assim, a função principal é definida de acordo com o objeto e seu uso, sendo sempre acompanhada das outras funções. A função prática não pode excluir a função estética, existindo ainda, uma estreita relação entre função estética e simbólica. Segundo definições de Löbach para cada uma das funções, entende-se por:

I. Função prática: são as relações entre produto e usuário nos efeitos diretos e fisiológicos do uso, e a capacidade do produto em atender a uma necessidade de uso com funções práticas adequadas para o uso final.

II. Função estética: Löbach (2001, p. 171) afirma que a "percepção é um processo pelo qual uma aparência estética se transforma em significado".

III. Função simbólica: Para Löbach (2001, p.64-65) é aquela função que é determinada por "aspectos espirituais, psíquicos e sociais do uso [...] estabelece ligações com suas experiências e sensações anteriores". A configuração simbólica deriva dos aspectos estéticos do produto e se manifesta por meio de seus elementos constituintes.

Löbach (2001) ainda aponta questões acerca das funções a serem observadas no design do produto, dentre as quais destaca-se:

- O designer deve conhecer as múltiplas necessidades e aspirações dos usuários e grupos de usuários, de forma a poder dotar o produto com as funções adequadas a cada caso ( $\mathrm{LÖBACH}$, 2001, p. 55);

- Os objetos utilitários são usados também para satisfazer as necessidades estéticas. Com frequência, esta necessidade não é reconhecida e é suplantada por outras "mais necessárias à vida". A verdade é que, segundo Löbach, a satisfação das necessidades estéticas não é necessária para nossa existência física, mas à nossa saúde psíquica. (LÖBACH, 2001, p. 35);

- Os produtos possuem diversas funções, que podem ser hierarquizadas pela importância. "(...) A função principal está sempre acompanhada de outras funções secundárias de acordo com as múltiplas necessidades e aspirações dos usuários. (LÖBACH, 2001, p. 54-55)”.

\subsection{A cor funcional}

A cor é uma importante ferramenta na configuração dos produtos, sendo um atributo para o desenvolvimento de um bom projeto de produto. A universalidade das cores possui uma força 


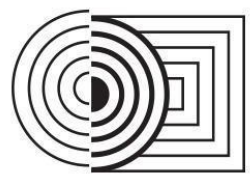

\section{$17^{\circ}$ ERGODESIGN \& USIHC 2019 \\ PUC-Rio, 11 a 13 de dezembro \\ Rio de Janeiro, RJ, Brasil}

$17^{\circ}$ Ergodesign - Congresso Internacional de Ergonomia e Usabilidade

de Interfaces Humano Tecnológica: Produto, Informações Ambientes Construídos e Transporte

$17^{\circ}$ USIHC - Congresso Internacional de Ergonomia e Usabilidade

de Interfaces Humano Computador

comunicativa bastante diversa e está intimamente ligada com a tarefa executada, sendo um meio de auxiliar no desempenho e segurança de produtos, de trabalhadores bem como do espaço ao qual está inserida (ALEXANDRIA; GONÇALVES, 2012). A cor é uma linguagem não verbal capaz de comunicar ideias. Como elemento informacional, promove o entendimento e reforça a comunicação através de linguagem própria com significado e aplicação segundo sua função, antecipando a interpretação da mensagem (NUNES, 2012).

Assim, a cor é capaz de emitir mensagens e significados ao usuário, podendo exercer o papel de provocadora nas reações e emoções humanas, e esses aspectos desempenham grande influência na usabilidade do produto (ELY, 2016; GANEM; LINHARES; GUEDES, 2014). Rangel (2011) aponta que a escolha da cor não deve ser aleatória e nem baseada em promover apenas produtos visualmente atraentes, mas sim, por meio de um mapeamento do contexto da cor, que consiste no levantamento com e sobre o usuário, do produto, da tarefa e da informação que se deseja transmitir.

Segundo Rangel; Matos; Tigre (2013) as especificações das cores dos produtos para ambientes residenciais, de um modo geral, têm seguido ao longo de décadas as macrotendências e tendências de estilo, configuradas a partir de pesquisas de estilos de vida da população mundial, sobretudo, nos grandes centros formadores de opinião, dentre os quais ressaltam-se Nova York, Tóquio, Paris, São Paulo e Milão. No entanto, Rangel (2016) defende que a elaboração de uma cartela de cores em consonância com as tendências é apenas um dos indicadores de uso da cor no produto. Rangel (2016) destaca a cor em seu uso funcional e, consequentemente, a pertinência de sua configuração segundo as funções de Löbach (2001). Assim, existem questões inerentes às cores e ao seu uso que podem ser visualizadas como pertinentes às funções prática, estética e simbólica apontadas por Löbach (2001) e trabalhadas no contexto do processo do projeto.

No que se refere à interface cor $\mathrm{x}$ produto $\mathrm{x}$ usuário, a função prática da cor decorre da visibilidade $\mathrm{e}$ da legibilidade conferida pelos contrastes cromáticos e da distribuição da cor na forma (GUIMARÃES, 2004; UEBELE, 2007 apud RANGEL, 2016), em auxílio ao melhor entendimento, usabilidade e segurança do produto (MORAES, 2001, apud RANGEL, 2016).

Quanto à função estética, as cores não podem se ater à beleza como um fim, e sim em sensibilizar os sentidos humanos (pelo menos um deles). Assim, a cor no produto decorre das tendências de estilo vigentes no mercado, bem como, segundo Löbach (2001), de sua manipulação de maneira que se relacione harmoniosamente com a forma e demais elementos do objeto, cumprindo a função de atração e de sedução dos usuários. Isso significa, para Rangel (2016), que as cores dos materiais devem ser distribuídas com equilíbrio, de maneira a prover nos usuários diversas sensações vinculadas ao belo: o conforto visual, o bem-estar, a tranquilidade e a segurança. Entendendo que harmonia não é sinônimo de monotonia, em que não se possa trabalhar com contrastes cromáticos mais ousados (RANGEL, 2016), contudo, sempre norteado pelo princípio de que a função estética visa o equilíbrio para não gerar desconforto visual (ARNHEIM, 2004; GUIMARÃES, 2004 apud RANGEL, 2016).

Cada cultura possui a sua forma de se expressar através da cor, atribuindo significados, valores, sensações e ideias. Existem, portanto diversos signos cromáticos culturais, e muitas cores têm significados diferentes entre as culturas (LACY, 2009; PASTOUREAU, 1997). Como função simbólica, é importante que a cor imponha significados aproximados ao universo do usuário, concedendo ao produto um valor simbólico (HELLER, 2009; PASTOUREAU, 1997) e uma identidade de maneira tal que induza nesse a sensação de reconhecimento e pertencimento ao seu ambiente (RANGEL, 2016). 


\section{$17^{\circ}$ ERGODESIGN \& USIHC 2019 \\ PUC-Rio, 11 a 13 de dezembro \\ Rio de Janeiro, RJ, Brasil}

$17^{\circ}$ Ergodesign - Congresso Internacional de Ergonomia e Usabilidade

de Interfaces Humano Tecnológica: Produto, Informações Ambientes Construídos e Transporte

$17^{\circ}$ USIHC - Congresso Internacional de Ergonomia e Usabilidade

de Interfaces Humano Computador

As figuras 1, 2, e 3 apresentam exemplos de uso da cor com a funções prática, estética e simbólica, respectivamente.

Figura 1 - Lixeiras para separação do lixo com cores diferenciadas.

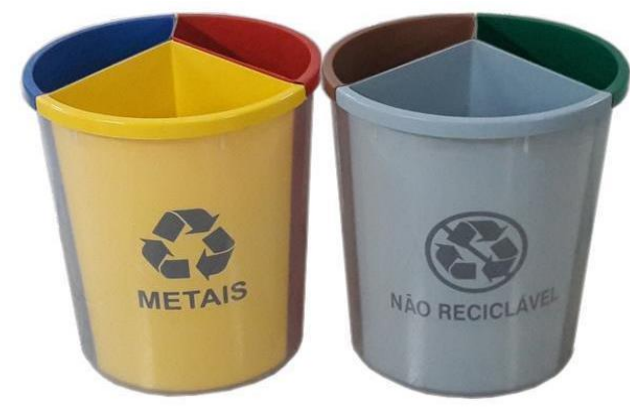

Fonte: Superma Clean ${ }^{1}$ (uso permitido)
Figura 2 - Mesas escolares infantis com cores diversas

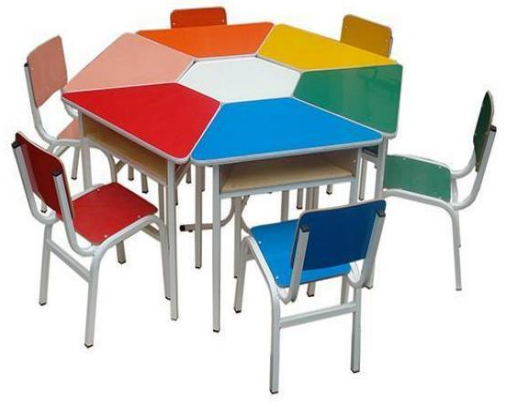

Fonte: Brinquedo barato ${ }^{2}$ (uso permitido)
Figura 03 - sinalização para pedestres através de luzes coloridas na pavimentação.

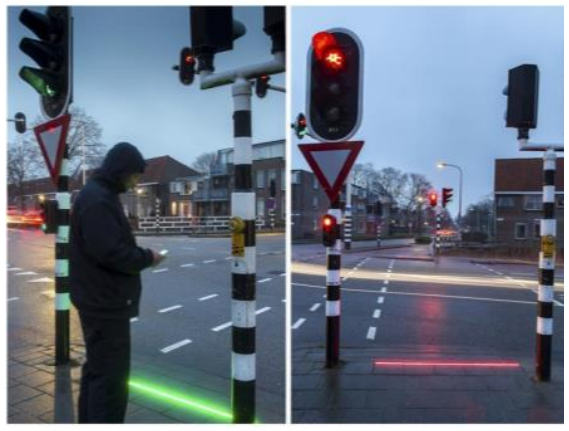

Fonte: Practica español ${ }^{3}$ (uso permitido)

\subsection{O projetista e a cor no projeto de produto}

A práxis do Design envolve ação prática, apoiada por um corpus teórico, norteada por métodos de projeto. No entanto, Lawson (2011) se posiciona quanto ao processo do projeto não se apresentar em fases estanques e sequenciais. É um processo contínuo; muitas vezes é necessário gerar soluções para emoldurar o problema e entendê-lo em profundidade. O modelo do ato de projetar (Lawson, 2011), tem enfoque nas habilidades/valores dos projetistas e apresenta fases do processo de projeto pertinentes aos pensamentos, atitudes e habilidades do projetista, frente ao desafio de desenvolver um trabalho sob a visão do projeto como solução de problemas.

Bomfim (1997) disserta acerca da natureza interdisciplinar do projeto de Design, afirmando ser a interdisciplinaridade inerente à prática do Design, cuja variabilidade e a complexidade dos temas tratados por esse campo, não determinam um conjunto de conhecimentos comum à resolução de todos os possíveis problemas práticos. Dessa forma, um projeto configura-se a partir de uma equipe multidisciplinar que irá desenvolver os diversos projetos elencados ao projeto do objeto. Nesse contexto, Rangel (2016) afirma que a cor por suas características e especificidades deve ser definida a partir de um processo metodológico que se inicia com o desenvolvimento do projeto. Teixeira (2015, p. 182) corrobora ao fazer o seguinte questionamento: "Fazendo a dimensão cromática parte integrante da vida humana, por que não faz a mesma parte do processo de Design desde o seu início?".

Para Teixeira (2015, p.159) os profissionais (designers) devem entender que a cor não é um elemento somente cultural, e como integrante do projeto no design de produto não está apenas no

\footnotetext{
${ }^{1}$ Disponivel em: <http://www.supremaclean.com.br/lixeiras/imagens>

2 Disponível em: <http://www.brinquedobarato.com.br/loja/index.php/mobiliario-escolar/conjunto-trapezio-infantil-cada.html>

${ }^{3}$ Disponível em: <https://www.practicaespanol.com/pt/semaforos-no-chao-em-holanda-para-os-viciados-em-celular/>
} 
nível mercadológico, está, sobretudo, no nível do consumidor enquanto utilizador do produto desenhado e da relação de ambos.

Ely (2016) aponta que os designers fazem relação entre cor e emoção, e ao responderem sobre a sua formação específica de cores apenas um professor estrangeiro apontou ter estudado a cor e seu uso, os outros apostam na sua sensibilidade e/ou estudaram por conta própria e/ou aprenderam na prática, e ainda, um deles não demonstra muito interesse pelo assunto cor no projeto. Outra questão apontada na pesquisa de Ely (2016) é a de que os respondentes apontam a pesquisa com o usuário no final do processo de delinear a cor no produto.

De uma maneira geral, pode-se concluir que os respondentes entendem não terem tido na graduação conteúdo mais aprofundado sobre as cores, sobretudo seu uso no projeto. Conforme Ely (2016), para um "é uma questão de facilidade [...] uso mais a sensibilidade", para outro "trivial" com abordagem sobre "combinações e percepção [...] aprendeu na prática do design na tentativa de se aproximar do público."

Essa falta de aporte teórico voltado ao uso da cor no produto, aliado aos valores dos respondentes em buscar ou não maior compreensão do assunto tem influência verificada na prática profissional. Nesse sentido Ely (2016, p.75) aponta que:

Como parte dos resultados, é notável que não existe um padrão ou requisitos para o ensino sobre as cores. Além disso, parece não haver uma sistematização metodológica para o uso das cores no produto. [...] Com relação a técnicas [...] a pesquisa com os usuários e abordagens a questões culturais estão presentes em vários métodos ou estratégias metodológicas de forma mais sofisticada do que a descrita pelos entrevistados.

\subsection{Ergonomia e cor}

A Ergonomia é um campo que se volta para o Sistema Homem, Tarefa, Máquina (SHTM) (MORAES; MONT'ALVÃO, 2001), ou seja, visa compreender as interações desse sistema para prover produtos, serviços, trabalho, ambientes reais e virtuais de condições passíveis de não gerar custos humanos. $A$ ergonomia estuda o impacto do trabalho ao ser humano, compreendendo o trabalho em um sentido amplo com "as situações em que ocorre o relacionamento entre o ser humano e uma atividade produtiva de bens ou serviços" (IIDA \& BUARQUE, 2016, p. 2).

Segundo lida \& Buarque (2016, p.1) "a ergonomia expandiu-se horizontalmente, abarcando quase todos os campos de atividades humanas". Tal expansão tem maior direcionamento para o setor de serviços e no estudo de certas minorias, tais como os idosos, obesos e pessoas com deficiência. Mudanças ocorridas no trabalho apontam uma dependência principalmente dos aspectos cognitivos, isso significa dizer da percepção, processamento da informação e da tomada de decisões (IIDA \& BUARQUE, 2016, p. 1). lida \& Buarque (2016, p.257) apontam que além de questões biomecânicas, fisiológicas e cognitivas, a ergonomia se volta para as questões emocionais no relacionamento com os produtos.

Para Wisner (1987 APUD IIDA \& BUARQUE, 2016, p.18) a ergonomia de concepção é uma das aplicações da ergonomia e ocorre na concepção do produto, da máquina, ambiente ou sistema, sendo o melhor momento pois "as alternativas poderão ser melhor examinadas". Do ponto de vista ergonômico, os produtos são considerados como meios para que o ser humano possa executar 


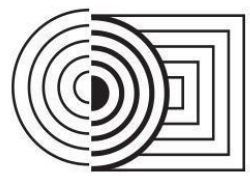

\section{$17^{\circ}$ ERGODESIGN \& USIHC 2019 \\ PUC-Rio, 11 a 13 de dezembro \\ Rio de Janeiro, RJ, Brasil}

$17^{\circ}$ Ergodesign - Congresso Internacional de Ergonomia e Usabilidade

de Interfaces Humano Tecnológica: Produto, Informações Ambientes Construídos e Transporte

$17^{\circ}$ USIHC - Congresso Internacional de Ergonomia e Usabilidade

de Interfaces Humano Computador

determinadas funções. Esses produtos, então, passam a fazer parte de sistemas humano-máquinaambiente.

Gomes Filho (2006) aponta a cor como um requisito do projeto inserido nas ações de percepção vinculada ao sentido da visão, relacionado às formas e cores. Gomes Filho (2016) argumenta que a cor como um código operacional, de segurança, que serve para indicar, alertar, chamar atenção e reduzir erros de manuseio a fim de evitar acidentes no ambiente de trabalho. Sua utilização deve obedecer a normas e regras específicas sobre significados e aplicações exatas das cores para determinadas funções. O uso adequado das cores facilita a comunicação dos usuários reduzindo erros e aumentando a eficiência no trabalho.

Verifica-se, portanto, o uso da cor sob os conceitos da visibilidade, legibilidade e usabilidade.

A visibilidade é uma qualidade que torna algo visível, ou seja, sua capacidade de ser captado pelos sentidos humanos em meio a outros estímulos, que atrai a atenção e prende a visão. Segundo lida (2005) cores de grande visibilidade devem ser usadas quando se quer atrair a atenção, mas não permanentemente para não se tornar fatigante.

A legibilidade resulta no reconhecimento e identificação clara e precisa da mensagem que se quer transmitir, sugerindo que a informação está composta dentro do princípio da boa organização em que as partes podem ser reconhecidas e organizadas num modelo coerente, como descrito por lida; Buarque (2016) e Gomes Filho (2006 e 2016).

A usabilidade tem como característica principal a eficiência, a facilidade de executar uma ação, comodidade e segurança no uso dos produtos em ambiente doméstico e profissional, auxiliando na facilidade de manuseio, adaptação antropométrica e biomecânica, na compatibilidade de movimentos, além do fornecimento claro de informações e facilidade de "navegação" quando aplicado em softwares (IIDA; BUARQUE, 2016). Um produto ou serviço com boa usabilidade deve ter interação entre os produtos e usuários, em tarefas e ambientes para produzir qualidade funcional, assim como alcançar objetivos e um uso amigável do produto.

Outra questão da qual a ergonomia tem se ocupado nas últimas décadas e pertinente à cor no produto é a agradabilidade. A ergonomia agrega agradabilidade aos produtos e serviços ao se voltar para a dimensão do prazer, passando do nível físico/fisiológico para o nível psicológico/emocional. Segundo lida; Buarque (2016, p.262) "a agradabilidade dos produtos visa proporcionar prazer estético e simbólico ao consumidor”. Dessa forma, a agradabilidade vem somar à usabilidade as emoções evocadas pelos produtos.

\subsection{Design centrado no usuário}

O termo Design Centrado no Usuário (DCU) pode ser caracterizado como sendo uma construção de um design afetivo, que leva em consideração os interesses e as necessidades do usuário, colocandoo no centro do processo criativo de desenvolvimento do produto onde são consideradas as características, necessidades e desejos das pessoas que efetivamente usarão tais produtos (KULPA ET AL, 2011). Kulpa (Et Al, 2011) ainda afirma que as implicações deste conceito, mesmo sendo muito simples, são surpreendentemente complexas. 


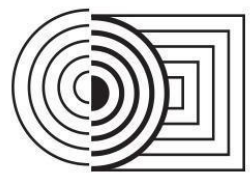

\section{$17^{\circ}$ ERGODESIGN \& USIHC 2019 \\ PUC-Rio, 11 a 13 de dezembro \\ Rio de Janeiro, RJ, Brasil}

$17^{\circ}$ Ergodesign - Congresso Internacional de Ergonomia e Usabilidade

de Interfaces Humano Tecnológica: Produto, Informações Ambientes Construídos e

Transporte

$17^{\circ}$ USIHC - Congresso Internacional de Ergonomia e Usabilidade

de Interfaces Humano Computador

Ao se projetar um produto, o designer deve entender que é importante definir o público alvo observando características em relação a sexo, faixa etária e nível socioeconômico, além dos aspectos culturais que podem influenciar no uso desse produto, com isso, a cultura também pode influenciar na escolha das cores e modificar a interação com os usuários (KULPA ET AL, 2011).

Todas as experiências que o usuário tem enquanto faz uso de um produto, deveriam ser o resultado de uma decisão consciente do designer, para com a escolha e aplicação correta das cores, sendo fruto do tempo gasto procurando as melhores soluções.

\section{MATERIAIS E MÉTODOS}

O presente trabalho se insere no âmbito de uma pesquisa exploratória que tem por definição, segundo Gil (2008), proporcionar maior familiaridade com o problema no sentido de torná-lo claro. Por investigar algo ainda pouco conhecido, a pesquisa exploratória, tende a ser flexível e se adaptar ao longo do desenvolvimento da pesquisa conforme o objetivo desta. A coleta de dados permeia técnicas como levantamento bibliográfico, entrevistas com pessoas experientes, e análise de exemplos que estimulem a compreensão (GIL, 2008).

Além do levantamento bibliográfico, a técnica utilizada para levantamento de dados foi o questionário com perguntas abertas e fechadas. As perguntas fechadas são aquelas em que as respostas são prédefinidas, baseadas em argumentos elaborados anteriormente pelo pesquisador e as perguntas abertas, propiciam uma maior liberdade ao entrevistado de responder com as suas palavras. $O$ documento com o questionário foi, submetido ao Comitê de Ética da Pesquisa para sua validação e todos os respondentes assinaram o termo de livre consentimento.

Para o grupo da amostra, foram considerados os especialistas, ou seja, profissionais - (arquitetos e designers) - que atuam diretamente com desenvolvimento e/ou especificações de produtos residenciais com experiência de trabalho nesse segmento. O método de seleção da amostra é o nãoprobabilista intencional, de modo que no universo a ser pesquisado, nem todos os indivíduos têm possibilidades iguais de serem selecionados, pois não possuem as características específicas desejadas (LAVILLE; DIONNE, 1999). Dessa forma, foi desenvolvida uma lista de profissionais das áreas de arquitetura e design, com representantes das cidades de São Paulo, Rio de Janeiro e Juiz de Fora. O contato foi feito principalmente online e também por telefone.

Essa pesquisa se interessa pela cor no seu uso funcional e qual a sua inserção nos projetos, aproximando-os ao usuário real, sendo assim a visão dos projetistas é importante para elucidar dúvidas e ratificar (ou refutar) os dados acerca da cor no produto. Os especialistas detêm as informações acerca de suas intenções, limitações e possibilidades na concepção e implantação dos projetos. Dessa forma, o questionário objetivou conhecer as técnicas e meios de seleção de cores utilizadas pelos profissionais, para compreender como a escolha da paleta no projeto pode ser orientada para o bem-estar do usuário.

\section{RESULTADOS E DISCUSSÃO}

A partir do contato com os especialistas, foram listados 67 profissionais das áreas de arquitetura e design, para o envio dos questionários. A participação foi de $20,89 \%$, ou seja, número de questionários considerados foi de 14 . O questionário foi elaborado com perguntas fechadas e abertas 
$17^{\circ}$ ERGODESIGN \& USIHC 2019

PUC-Rio, 11 a 13 de dezembro

Rio de Janeiro, RJ, Brasil $17^{\circ}$ Ergodesign - Congresso Internacional de Ergonomia e Usabilidade de Interfaces Humano Tecnológica: Produto, Informações Ambientes Construídos e Transporte

$17^{\circ}$ USIHC - Congresso Internacional de Ergonomia e Usabilidade de Interfaces Humano Computador

e as questões foram categorizadas em: perfil; perfil profissional; metodologia de trabalho; desenvolvimento da cor no produto.

Quanto ao perfil e ao perfil profissional dos respondentes, a população constituiu-se de 11 mulheres e 03 homens, dentre esses a maioria são arquitetos $(n=7)$ e a maioria de todos os respondentes desenvolvem serviços autônomos $(n=11)$, conforme pode ser verificado na tabela 1 .

Tabela 1 - Sexo, profissão e tipos de projetos

\begin{tabular}{|c|c|c|c|c|c|}
\cline { 3 - 6 } \multicolumn{2}{c|}{} & \multicolumn{2}{c|}{ SEXO } & \multicolumn{2}{c|}{ PROJETOS } \\
\hline O QUE É & TOTAL & FEMINIMO & MASCULINO & AUTÔNOMO & EMPRESA \\
\hline ARQUITETO & 7 & 7 & 0 & 6 & 1 \\
\hline DESIGNER INTERIORES & 2 & 2 & 0 & 2 & 0 \\
\hline DESIGNER PRODUTO & 3 & 1 & 2 & 2 & 1 \\
\hline DESIGNER GRÁFICO & 1 & 1 & 0 & 0 & 1 \\
\hline PROJETISTA & 1 & 0 & 1 & 1 & 0 \\
\hline
\end{tabular}

Fonte: as autoras, 2018.

A faixa etária compreendida entre 25 a 29 anos tem o maior número de respondentes $(n=4)$.

No perfil profissional também foram indagadas as seguintes questões: (1) segmento profissional, (2) as categorias de mobiliário, (3) a quais cômodos essas categorias se inserem e os (4) tipos de móveis.

Pode-se verificar no Gráfico 01 que dentre os três tipos apresentados quando indagados sobre "qual segmento o profissional atua", todos $(n=14)$ trabalham com o serviço exclusivo de marcenaria, e além disso, a maioria também trabalha $(n=6)$ com o mobiliário planejado.

Gráfico 01 - Gráfico do segmento de mobiliário

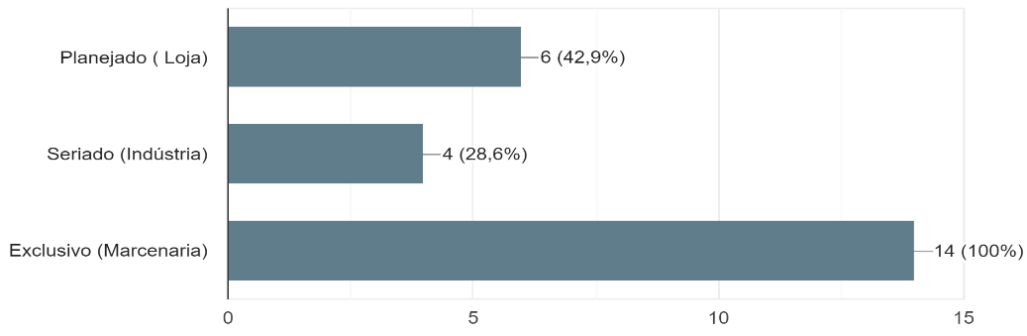

Fonte: As autoras, 2018.

Com relação às categorias em que o profissional exerce sua função, dentre elas Objetos Decorativos, Mobiliário Utilitário, Mobiliário Decorativo e Eletrodomésticos, é possível perceber que a maioria $(\mathrm{n}=11)$ trabalha com Mobiliário Utilitário.

O projeto para quartos, é desenvolvido pela maioria dos profissionais $(n=11)$, seguido do ambiente de sala de jantar $(n=10)$, e tendo cozinhas e sala de estar são desenvolvidas pelo mesmo número de profissionais $(n=9)$. 
$17^{\circ}$ ERGODESIGN \& USIHC 2019

PUC-Rio, 11 a 13 de dezembro

Rio de Janeiro, RJ, Brasil $17^{\circ}$ Ergodesign - Congresso Internacional de Ergonomia e Usabilidade de Interfaces Humano Tecnológica: Produto, Informações Ambientes Construídos e Transporte

$17^{\circ}$ USIHC - Congresso Internacional de Ergonomia e Usabilidade de Interfaces Humano Computador

Conforme por ser observado no Gráfico 02 dos diversos tipos de mobiliários listados, sendo possível observar que a maioria projeta armário $(n=11)$, seguido pela estante, home office e rack todos com o mesmo número de profissionais $(n=10)$.

Gráfico 02 - Gráfico dos tipos de mobiliário

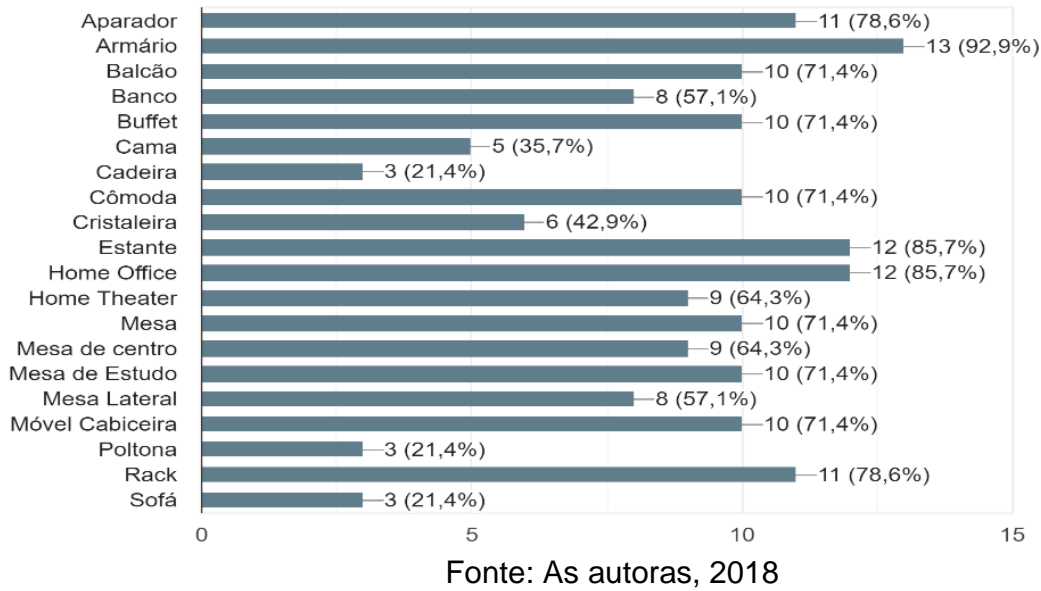

Para as categorias metodologia de trabalho e desenvolvimento da cor no produto os dados foram levantados por meio das seguintes perguntas abertas:

1. No seu método de criação de um novo produto, em qual(is) momento(s) você pensa na cor?

2. Faz levantamento das necessidades do usuário? Como?

3. Quais critérios você utiliza para a escolha e aplicação da cor no produto?

4. Define funções para a escolha da paleta e localização da cor no produto? Se sim, fale um pouco sobre como e quais as funções você define.

Os dados desses itens foram compilados segundo os conceitos e indicadores levantados a partir do referencial teórico. Deve-se pontuar que a identificação dos indicadores nas falas dos respondentes não ocorreu pela palavra literal e sim pelo sentido da frase que denota o significado do indicador de forma implícita. Esse procedimento se deu pelo fato do respondente em sua fala, de uma maneira geral, não se ater aos conceitos e sim em explicitar de forma mais livre o seu procedimento de trabalho.

Sobre as funções do produto identificou-se nas falas a busca de características como "praticidade e funcionalidade", como exemplo, o uso de um material ou cor diferente em uma gaveta para indicar sua existência facilitando ao usuário encontrá-la: "Destacar através da cor um puxador de gaveta, ou uma porta em outra tonalidade indicando que ali há uma gaveta/porta" (respondente 08).

Além disso verificou-se na fala dos respondentes a preocupação com a setorização, a função do ambiente, a intenção e a demanda do cliente.

Questões que envolvem as funções estética e simbólica do produto também foram elencadas ao gosto pessoal do projetista, ao gosto do usuário e a busca de unidade e/ou quebra de monotonia, causar sensações de amplitude ou redução de espaço. "As principais funções são por questões estéticas e sensoriais quando há interesse em ornar cores e materialidade" (respondente 05). 


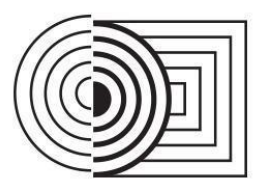

\section{$17^{\circ}$ ERGODESIGN \& USIHC 2019 \\ PUC-Rio, 11 a 13 de dezembro \\ Rio de Janeiro, RJ, Brasil}

$17^{\circ}$ Ergodesign - Congresso Internacional de Ergonomia e Usabilidade

de Interfaces Humano Tecnológica: Produto, Informações Ambientes Construídos e Transporte

$17^{\circ}$ USIHC - Congresso Internacional de Ergonomia e Usabilidade

de Interfaces Humano Computador

Quanto à Ergonomia os respondentes, de uma maneira geral, não se referem à Ergonomia como uma disciplina da qual recorrem às técnicas para a investigação do usuário/produto/contexto. No entanto, falam sobre "entrevista com o cliente"; "conversas com os clientes definem necessidades e gostos"; captar necessidades por meio do setor de marketing da empresa, pelo setor comercial, vendedores e lojistas "que são os formadores de opinião" (respondentes 04, 13 e 05, respectivamente).

Outros pontos abordados vinculados ao produto e à sua forma, "material" e "cor" situam-se nos conceitos de usabilidade, legibilidade e visibilidade, tais como, "necessidade de armazenamento, espaços necessários, local para leitura"; "usabilidade", "acessibilidade, segurança, ergonomia, funcionalidade"; "satisfação do usuário"; "produto e sua cor tem a função de destaque ou contraste com o ambiente" (respondentes 01, 03, 08 e 11); o produto dentre outras coisas deve transmitir sensações passível de entendimento pelo usuário.

Questões como o produto gerar destaques e setorização estão também vinculadas ao desenvolvimento de um código visual gerador de identidade capaz de destacar o produto e torná-lo único dentre os demais.

Quanto à Cor nos produtos residenciais, todas as perguntas permearam o tema. A composição das cores segue as tendências contemporâneas de cores captadas em feiras nacionais e internacionais, sites, birôs de estilos e as cores lançadas por empresas influenciadoras de tendências de cor tais como a Pantone (americana) e a NCIS (sueca); busca de cores que combinem entre si; escolha das cores pensando no espaço e no gosto do cliente/usuário; utilização de uma cor base e alguns destaques de cores com contraste à cor base; pensar na forma, função e acabamento. Segundo o respondente 04, "as cores são escolhidas de acordo com a intenção do espaço, mais claros, mais aconchegantes, mais práticos, mais limpos ou sépticos".

Segundo os respondentes, as estratégias para o uso da cor no produto iniciam-se no contato com o cliente (na fase do pré-projeto) e são revistas e/ou ajustadas durante o processo de desenvolvimento. O relato do respondente (10) encerra o pensamento de outros relatos pertinentes a projetos exclusivos/sob encomenda (em que há contato direto com o usuário e o ambiente no qual o móvel será inserido): "Pré-escolha da cor quando é definido o estilo do ambiente, poderá haver escolha da cor para equilíbrio de volumes; personalidade dos clientes, estilo do ambiente".

O respondente (01) aponta que a cor surge do diálogo com as demais cores do ambiente. Os respondentes $(04,08$ e 11) indicam escolher a cor no final do processo de desenvolvimento do produto. Segundo eles, respectivamente, a cor é escolhida "no final do desenvolvimento do projeto", "no final" e "quando a volumetria está pronta".

Aspectos da teoria da cor também foram percebidos na fala dos respondentes quando dizem que utilizam a psicologia das cores para atribuir os significados, ou seja, "a partir das tonalidades as cores exercem influências emocionais"; indicam que as cores têm "funções e significados"; buscam conhecer a teoria para tirar partido dos contrastes cromáticos "obter o contraste desejado para um bom resultado final" (respondentes, 04, 06 e 14).

$\mathrm{Na}$ fala dos respondentes fica claro o uso das funções (Löbach, 2001). Na função prática questões como funcionalidade, com o intuito de facilitar o uso foi recorrente, assim como para as funções estéticas e simbólicas verifica-se o cuidado em criar uniformidade ou quebra de monotonia ou atmosfera de conforto ou busca do estilo do ambiente e do cliente; além de entender o ambiente onde será inserido o produto e as tendências do segmento (adaptadas à nossa cultura, clima e estilo de vida). Esses pontos estão inseridos à teoria que trata das funções e da cor, apresentadas no referencial teórico. 


\section{$17^{\circ}$ ERGODESIGN \& USIHC 2019 \\ PUC-Rio, 11 a 13 de dezembro \\ Rio de Janeiro, RJ, Brasil}

$17^{\circ}$ Ergodesign - Congresso Internacional de Ergonomia e Usabilidade

de Interfaces Humano Tecnológica: Produto, Informações Ambientes Construídos e Transporte

$17^{\circ}$ USIHC - Congresso Internacional de Ergonomia e Usabilidade

de Interfaces Humano Computador

A pesquisa com os profissionais corroborou aspectos levantados na teoria e apontou que os mesmos não se atêm a discursos teóricos sobre a Ergonomia e a cor. Percebe-se muitas vezes nas falas certa empiria, no uso desses temas em seus projetos. Embora as práticas sejam diferentes e denotam maior ou menor aporte teórico no uso da cor, para os especialistas respondentes da pesquisa, 0 estudo da cor e sua aplicação é feita seguindo os três princípios: teoria, composição e estratégia. A seguir faz-se alguns destaques de palavras das falas dos respondentes.

- Teoria seguindo a psicologia das cores: influências emocionais, contraste, funções e significados.

- Composição: pré escolha da cor, paletas, tendências, harmonia, atmosfera de conforto, setorização, forma, função e acabamento;

- Estratégia: cor definida de acordo com o estilo do ambiente, durante o desenvolvimento ou ao final.

Os respondentes apontam que os produtos residenciais, sobretudo os fabricados em série tais como sofás e cadeiras, derivam de um equilíbrio entre forma, volumes e cores, que irão configurando o produto no desenvolvimento de projeto. No entanto, há uma silhueta pré-definida a partir do briefing criado junto ao cliente. Suas falas corroboram, de modo geral, uma preocupação com um projeto funcional, belo e a satisfação do usuário. Embora não demonstrem conhecimento sobre dimensão da pesquisa com o usuário.

Destaca-se a consonância dos resultados com Ely (2016, p.75) quando aponta que "não há uma padronização de uma sistematização metodológica para o uso das cores no produto" e ainda, os profissionais não se atêm em "métodos ou estratégias metodológicas", mesmo quando apontam que visam a satisfação do usuário. Não veem a cor como um projeto (RANGEL, 2016), e acredita-se que o fato de pensarem no usuário e na cor desde o início do projeto, em contraponto a Teixeira (2015), é por trabalharem com produtos de marcenaria e planejado que em sua maioria necessita do contato com o usuário na fase inicial.

O presente estudo apontou que há pouca diferença entre a prática profissional, no que tange à cor, no desenvolvimento de produtos industriais (ELY, 2016; TEIXEIRA, 2015), ou planejados, ou de marcenaria. E ainda, que há deficiência no ensino da cor $(E l y, 2016)$ e isso pode ser influente na prática profissional.

A contribuição desse estudo está em ampliar a compreensão acerca da prática profissional para extrair indicadores para novos levantamentos de dados. Como desdobramento, uma nova pesquisa está em curso de execução e busca elaborar um protocolo para investigação da percepção do usuário em relação aos produtos residenciais, com vistas a cruzar, em estudos futuros, os dados com a percepção dos especialistas, a serem ampliados em outro momento da pesquisa.

\section{REFERÊNCIAS BIBLIOGRÁFICAS}

ALEXANDRIA, Rosângela Pereira De; GONÇALVES, Patrícia Passos. Percepção da Cor: A Influência da Cor como informação em anúncios publicitários. São Paulo, Revista UNESP, 2012.

BRAIDA, Frederico; NOJIMA, Vera Lúcia. Tríades do design: Um olhar semiótico sobre a forma, o significado e a função. Rio de Janeiro: Rio Books, 2014.

BOMFIM, G. A. Fundamentos de uma teoria transdisciplinar do design: morfologia dos objetos de uso e sistemas de comunicação. Estudos em design, Rio de Janeiro, v. 5, n. 2, p. 27-41, 1997. 
ELY, Cristina. Processo de seleção de cores no projeto de produto orientado ao bem-estar. 2016. 80f. Dissertação (Mestrado) - Universidade Federal do rio Grande do Sul, Escola de engenharia, Porto Alegre, BR-RS, 2016.

GANEM, Adizza de Carvalho; LINHARES, Fernando de Oliveira; GUEDES, João Batista. A cor no produto, um experimento metodológico. Rio de Janeiro, TRÍADES em Revista, 2014

GIL, A. C. Como elaborar projetos de pesquisa. São Paulo: Atlas, 2008.

GOMES FILHO, João. Design do Objeto: bases conceituais. São Paulo: Escrituras Editora, 2006.

GOMES FILHO, João. Ergonomia do Objeto: Sistema Técnico de leitura ergonômica. São Paulo, Escrituras Editora, 2016.

HELLER, E. Psicologia del color: cómo actúan los colores sobre los sentimientos y la razón. Barcelona: Editorial Gustavo Gili, 2009.

IIDA, I. Ergonomia: projeto e produção. São Paulo: Edgard Blücher, 2005.

IIDA, I. BUARQUE, L Ergonomia: projeto e produção. São Paulo: Edgard Blücher, 2016.

KULPA, Cínthia Costa; PINHEIRO, Eluza Toledo; SILVA, Régio Pierre da. A influência das cores na usabilidade de interfaces através do design centrado no comportamento cultural do usuário. Porto Alegre, UFRGS, 2011.

LACY, Marie Louise. O poder das cores no equilíbrio dos ambientes. São Paulo, $12^{\circ}$. ed. São Paulo: Pensamentos, 2009.

LAVILLE, C.; DIONNE, J. A construção do saber. Porto Alegre: Artmed; Belo Horizonte: UFMG, 1999. LAWSON, B. Como arquitetos e designers pensam. São Paulo: Oficina de Textos, 2011

LÖBACH, B. Design industrial: bases para a configuração dos produtos industriais. s. I.: Edgar Blücher, 2001.

MORAES, A.; MONT'ALVÃO, C. Ergonomia, conceitos e aplicações. Rio de Janeiro: iUsEr, 2003.

NUNES, Ana Camila Nobre Xavier. Informação através da cor: a construção simbólica psicodinâmica das cores na concepção do produto. Florianópolis, Revista Udesc, 2012.

PASTOUREAU, M. Dicionário das cores do nosso tempo. Lisboa: Editorial Estampa, 1997.

RANGEL, M. M. Cor e ergonomia do ambiente construído: uma investigação da orientação espacial em um ambiente hospitalar. 2011. 255f. Dissertação (Mestrado em Design) - Pontifícia Ủniversidade Católica do Rio de Janeiro, Departamento de Artes e Design, Rio de Janeiro, 2011.

RANGEL, M. M. Projeto cromático para sistemas informacionais: proposta para o uso da cor em wayfinding para estabelecimentos assistenciais de saúde. 2016. 298f. Tese (Doutorado) - Pontifícia Universidade Católica do Rio de Janeiro, Departamento de Artes e Design, Rio de Janeiro, 2016.

RANGEL, M. M.; MATOS, L. I; TIGRE, P. B. Relatório: Macrotendências do Design. Contrato SENAI FUJB Instituto de Economia da UFRJ. 2013.

TEIXEIRA, Ana Rita vieira Matias da Trindade. A cor enquanto elemento no projecto do design de produto. 2015. 182f. Dissertação (Mestrado em Design) - Universidade de Lisboa, Faculdade de Belas Artes, 2015.

\section{AGRADECIMENTOS}

Ao Instituto Federal de Educação, Ciência e Tecnologia, à FAPEMIG e ao CNPq pelo fomento e apoio à esta e outras pesquisas. 